\title{
External Influences on Students' Choice of Clothing in Takoradi Polytechnic
}

\author{
${ }^{*}$ Azuah, S. ${ }^{1}$, Aigbvboa, C.O. ${ }^{2}$ \\ ${ }^{1}$ Department of Fashion and Technology, Takoradi Polytechnic, Ghana \\ ${ }^{2}$ University of Johannesburg, Doornfontein Campus, Johannesburg, South Africa, \\ *schazuah@yahoo.com
}

\begin{abstract}
Clothing is an important factor in the interpretation of body image which affects the response behaviour of the beholder. A person's appearance profoundly affects the way he or she is treated by others at home, social gathering, market, job area, office or school. Selecting clothing requires careful considerations. The purpose of the study was to find out external influences on students' choice of clothing in Takoradi Polytechnic. The research design was descriptive. Questionnaires and focus group discussion guide were used. Departments of Fashion and Accounting participated with respondents chosen through stratified random sampling. Sample consisted of 207 with a total population of 699 students, 77 males and 130 females. Study revealed students dress casually for lectures instead of formally because casual wear could take any form. Male students' were normally driven internally indicating individuality while female students were mostly externally directed. Both sexes would least choose clothing for warm relationship. The more individuals they were aware of their inner feelings, the more differentiation they exhibited in their choice of clothing. This is contrary to the general perception that students or the youth choice of clothing is socially driven. However, some external factors were also quite significant in students' choices and should be given close attention if youth clothing are undesirable. This calls for continues education to streamline vital issues that are of significance to academic institutions and the African society as a whole.
\end{abstract}

\section{Keywords: Social factors, influence, clothing, students}

\section{Introduction}

While others think ones' dressing should not bother anyone, others hold the belief that one's appearance should be acceptable in the setting he or she belongs. As a trader chooses clothing to match the activities of the day, so will a student's dress code suit the school environment. Dress code, according to Pauly (2008), is a set of rules, as in a school, indicating the approved manner of clothing. A casual observation of the hallways of many higher institutions today reveals that students have pushed dress code to the limit, Fayokun, Adedeji, Oyebade 2009 stated. There are bare midriff, thigh underwear peeking above ultra lowcut jeans, and bright-coloured bras shining through sheer shirts. "It's getting out of control", said John Amaral (Wareham High School Principal) cited in Fayokun et al. (2009). In educational institutions, thus, the contention that in the absence of a prescribed school uniform or regulation on dress code in public schools will lead to resultant chaos can best be imagined. As a matter of fact, research has it that the dress regulation stabilizes the school classroom atmosphere, promotes decorum and has a real and reasonable connection with the successful operation of the educational system and with the maintenance of school discipline. This according to Fayokun et al. (2009) would be realised when choice of clothing on campus is founded more on cogent and tenable reasoning such as: upholding of academic standards, promotion of decorum and discipline in academic atmosphere, enforcement of morality and decency and security awareness.

Clothing and appearance are highly visible and allow others to formulate opinions or derive various cues about the wearer including personal information. 'Personal and social values are communicated through one's choice of clothing and appearance, and the manner in which an individual clothing expresses personal values'. Dibley (2004) concluded that values play a dominant role in guiding choices; consumers choose actions that produce desired consequences and minimise undesired consequences. Research again indicates that values affect behaviour (Kahle, 1996). Each individual possesses and follows a set of principles that guides thoughts and influences behaviour. The choice of clothing of the individual could depend on one's values that might result from the society they live in. Clothing and appearance provide us with some of the information needed to try to interpret others' thoughts, feelings, and actions. Society uses clothing and appearance cues to aid us in predicting the behaviour of others. As far as clothing is concerned, everybody is involved, whether in a naïve or a scholarly sense, Kaiser (1997). There are 
certain needs the individual gains through clothing either consciously or unconsciously. These among others are as stated in Maslow's hierarchy of needs such as physiological, security, social, esteem, and self-actualization needs. It would be appropriate for students to consider these in their choice of clothing. Dixon (2007) urged consumers to learn more about themselves in seeing how values have a role in influencing clothing and appearance. Values are self-organizing principles that guide our thoughts and actions (Kahle, 1996) and shape individual preferences and choices (Kaiser, 1997).

Statement of the Problems: It is often observed that students do not consider the implications of their choice of clothing and appearance but rather follow peers. Campuses of higher institutions today have fostered a climate for the display of seductive wears especially by students during lectures. There are halter-tops, bare midriff, 'I am aware', tight underwear showing above ultra-low-cut jeans, 'Ma tricky Jesus', 'Skinny', 'Apuskeleke' and bright-coloured bras shining through sheer shirts on every occasion.

Purpose of the Study: The purpose of the study was to investigate how Takoradi Polytechnic students choose their clothing. It also identified the external influences on the clothing types worn by students on campus, the body part(s) often exposed, and the motivations behind such clothing. The various channels under which students are influenced would be examined.

\section{Research Questions/Hypothesis}

- What types of clothing do students of Takoradi Polytechnic put on?

- What external factors influence students' choice of clothing and appearance?

- $\quad \mathbf{H}_{\mathbf{0}}$ - There is no significant different in students' choice of clothing with regards to gender.

- $\quad \mathbf{H}_{\mathbf{0}}$ - There is no significant different in students' choice of clothing with regards to programme.

Objectives of the Study: The research sought to determine the external factors influencing students' choice of clothing, significant difference in relation to departments (Fashion and Accounting) and, gender (male and female). The various channels under which students are influenced would be examined and the most influential ones figured out.

External Function of Clothing: Marshal et al. (2000) indicated that clothing is worn for the expression of status. Distinguished personalities in the society usually wear clothing to mark them out. Sometime, the noble and wealthy people dress to conform to their status in the society. In this category are presidents, first ladies, ministers, and people of high class in state functions and various occasions. Upper socioeconomic groups adapt fashion as symbols of distinction and exclusiveness, Simmel, 1973 explained. Students who want to belong choose clothing to fit the group they are associated with. Clothing is therefore, an important factor in the interpretation of body image that affects the response behaviour of the beholder. A student's appearance profoundly affects the way he or she is treated by others at home, social gathering, market, job area, office or school. Although clothing messages may sometimes be misinterpreted and falsified, Wallace (1985) warned that since clothing communicates 90 percent of an individual's qualities with which he/she is judged by others, clothing power should not be underestimated. Weber (1990) stated that a false impression created of an individual due to his or her clothing could change a person's life. This could mean difference between success and failure not only in interpersonal relations and professional careers but also in educational pursuit and in marriage. Clothing has been used to deceive people. It is regrettable that some people adopt extreme styles of clothing to create a false image about them. While some try to dress modestly, others care less about their clothing and appearance. Weber again concluded that either too much or too little concern with clothes may limit a person's life. The principle of dress code in tertiary schools is apparently to promote and embrace important values; cleanliness, neatness, modesty, decency and appropriateness in dressing which reflect initial dignity and sobriety through which students as well as staff and faculty represent the professional status of their respective disciplines. Wearing of tight, strapless and revealing clothes, or clothes whose lengths are above the knees on campuses are considered to be unsuitable, which supports Langner (1959) claimed that, the human body is less interesting or erotic when it is totally exposed.

\section{Methodology}

The study adopted a descriptive survey. The target population for the study consisted of Higher National Diploma (HND) students from the Departments of Fashion and Accounting in Takoradi Polytechnic in the Western Region of Ghana. The Department of Accounting had a total of 516 students made up of 410 males and 106 females, whilst that of Fashion had 183 students out of which, 33 were males and 150 
females (Takoradi Polytechnic 9th Congregation Brochure, 2010). Purposive sampling was used. The Department of Fashion was selected due to its link with the research whereas the Department of Accounting was for comparison purposes due to the differences in programmes of study. Random sampling (stratified) was used for the distribution of questionnaires. Sample size consisted of 207out of a population of 699 students. A total of 77 males resulting from 33 males from Fashion and 44 from Accounting was sampled. One hundred and thirty females participated, 70 from Fashion and 60 from Accounting. Results and discussions were based on close ended questions designed to unravel the external influences on clothing choices. Percentages and independence t-test were employed for the analyses. Popular views from focus group discussion were also sampled.

\section{Results and Discussion}

Results and discussions were based on Percentages and independence t-test.

Research Question 1: What types of clothing do students of Takoradi Polytechnic students wear? The most commonly clothing type used on campus was casual wear (59\%) This was followed by traditional (20\%) and formal clothes (19\%). The least types of clothes worn were occasional wears. During an interaction with some of the young students, one of them said, they dressed decently but in casual clothing. This is because casual wear could take any form; from provocative to the decency. Clothing for lectures which is supposed to be formal is overtaken by casual garments due to the individual perceptions about clothing. While others use clothing for self-fulfilment, excitement and fun, $10 \%$ do not actually care what they put on. Therefore, Watkins (1977) warned that clothing can affect a wearer's performance potential and can potentially distract his or her attention by shifting or causing some discomfort.

Table 1: Rating of types of clothing worn by students on various occasions

\begin{tabular}{lllll}
\hline ITEM & Formal & Traditional & Occasional & Casual \\
\hline Lectures & & & & \\
Church Service & $19 \%$ & $20 \%$ & $1 \%$ & $59 \%$ \\
Congregation/matriculation & $30 \%$ & $22 \%$ & $24 \%$ & $28 \%$ \\
Leisure time & $27 \%$ & $23 \%$ & $37 \%$ & $14 \%$ \\
Hall Week celebration & $11 \%$ & -- & -- & $89 \%$ \\
Total & $3 \%$ & $26 \%$ & $17 \%$ & $51 \%$ \\
\hline
\end{tabular}

The patronage of traditional wear seemed improving in the finding of this research. Students' desire for traditional wear recorded $(20 \%)$ for lectures. It took the second position in the total ranking on choice of clothing to various occasions. Times where students found in traditional clothing were considered old timer are over. Ghanaians are beginning to value their own cultural values. It also brings to the fact that local designers are beginning to bring out the uniqueness of our traditional fabrics. A finding that overturned Hansen's 2004 view that, something that is associated with mothers' and grandmothers' wear is considered old fashioned and looking best in "traditional clothing" therefore evokes a level of maturity.

Table 2: Body Part Exposure

\begin{tabular}{lccccccc}
\hline $\begin{array}{c}\text { Parts of } \\
\text { body }\end{array}$ & $\begin{array}{c}\text { Parts of } \\
\text { Breasts }\end{array}$ & $\begin{array}{c}\text { Upper } \\
\text { arm }\end{array}$ & $\begin{array}{c}\text { Upper } \\
\text { part } \\
\text { Buttock }\end{array}$ & $\begin{array}{c}\text { Shoulder } \\
\text { blade }\end{array}$ & Thighs & $\begin{array}{c}\text { None of } \\
\text { these }\end{array}$ & Total \\
\hline Frequency & 54 & 19 & 22 & 24 & 30 & 58 & 207 \\
Percentage & 26 & 9 & 11 & 12 & 14 & 28 & 100 \\
\hline
\end{tabular}

The study revealed that, majority of students, (28\%) do not mostly expose any of their body parts mentioned on table $1 \mathrm{~b}$. However, the next body parts students exposed were parts of the breasts $(26 \%)$ followed by thighs $(14 \%)$ and shoulder blades (12\%). Few students exposed their upper arm and the back waistline or the upper part of the two slopes of the buttocks (11\%) Table1b. The exposure of breasts and thighs is not appropriate for the school setting even though, it is in line with Westermarck cited in Dibley (2004) stance that the role of clothing is to display or emphasise the attributes of the body rather than concealing. In contrast, Langner (1959) claimed that the human body is less interesting or erotic 
when it is totally exposed. This type of clothing is found in Kaiser (1997) immodesty theory which states that clothing is used not to cover but to attract attention. The question is, should clothing in the school setting be chosen mainly to attract? A school is an academic institution with well defined guidelines, whose main aim is to ensure academic decorum with successful operation of the educational system and maintenance of school discipline (Fayokun et al., 2009). The choice of students' clothing should be founded more on cogent and tenable reasoning such as: upholding academic standards, enforcement of morality, decency and security awareness. Students' choice of clothing confirms Lynn, (2004), findings that shifting dress styles in the early to mid-20th century that exposed more skin and revealed a person's figure, created new definition in beauty today. This is also substantiated by Okwu's (2006) that, tertiary institutions of learning have been bedevilled with obscene dressing particularly by female students. Most girls go bare, depicting size and shape of the private parts with minis that barely skim the bottom. It appears now that to be fashionable regardless of where or who you are, one has to become half nude.

Research Question 2: What are the external factors that influence students' choice of clothing and appearance?

Table 3: Ratings of External factors (\% Respondents)

\begin{tabular}{|c|c|c|c|}
\hline Item & Important & $\begin{array}{c}\text { Barely } \\
\text { Important }\end{array}$ & $\begin{array}{c}\text { Not } \\
\text { Important }\end{array}$ \\
\hline Sense of belonging & 68.2 & 15.9 & 15.9 \\
\hline Warm relationships with others & 42.0 & 36.2 & 21.7 \\
\hline Being well-respected & 79.7 & 15.0 & 5.3 \\
\hline
\end{tabular}

Item

\begin{tabular}{lllll}
\hline & VO & 0 & $\mathrm{~S}$ & $\mathrm{~N}$ \\
\hline Involvement of friends in making clothing choices & 5.3 & 6.8 & 52.7 & 35.3 \\
Uncomfortable when my clothes are different from all others & 9.7 & 12.6 & 43.0 & 34.8 \\
Dress like friends in order to belong to a group & 3.4 & 4.8 & 11.6 & 80.2 \\
Feel more friendly and outgoing in certain clothing & 17.4 & 13.3 & 40.6 & 29.0 \\
Feel more part of the family when dressed like relatives & 19.8 & 18.8 & 34.8 & 26.6 \\
Family's opinion of my clothing more important than friends & 56.5 & 15.0 & 20.8 & 7.7 \\
School environment does not influence my choice of clothing & 26.1 & 10.1 & 34.8 & 29.0 \\
Keep my wardrobe up-to-date to be accepted & 13.0 & 10.1 & 30.0 & 46.9 \\
\hline
\end{tabular}

Scale: Very Often (VO), Often (O), Sometimes (S), Never (N)

What are the external factors that influence students' choice of clothing and appearance? The three main components of external factors in this study are sense of belonging, warm relations and being well respected. In addition to these components are the channels in which students are normally influenced. With regard to the sense of belonging, a social factor that deals with one being accepted and needed by the family, friends and community, $68 \%$ of respondents claimed sense of belonging was important in their choice of clothing. An equal percentage of $16 \%$ was each recorded for barely important and not important. For instance, on asking friends what they would wear to an event before the individual's choice of clothing, a greater percentage (53\%) responded they would sometimes seek friends' opinion. Contrarily, on choosing clothing similar to that of friends on campus and, dressing like friends, $63 \%$ and $80 \%$ responded in the negative (never) respectively. In comparative terms of belonging, between friends and family, $57 \%$ of respondents preferred selecting apparels suitable more to the family than friends. Also of interest was the influence of the school environment on students' choice of clothing. Thirty five percent indicated sometimes with the rest responses pretty close; very often $-26 \%$, often $10 \%$, and $29 \%$ for never.

On warm relationships with others, $42 \%$ of respondents claimed having close companionship and intimate friendship with other students was important in their choice of clothing, 36\% indicated barely important while the others estimated at $22 \%$ thought the factor as not important. Warm relationship among students is highlighted in students asking their friends what they are wearing to an event, getting new clothes for a special occasion when clothes are not similar to what friends are wearing. On these highlights however, 62 and $80 \%$ contradicted their stance about warm relationships in the choice of clothing as they claimed they never asked friends about what they would wear or buy clothing similar to friends. Eliciting responses from students with regards to the individual selecting clothing to be well- 
respected by others, $80 \%$ recognised the factor as important. Fifteen percent suggested it barely important but five percent indicated the factor as not important. However, when questioned about keeping a wardrobe up-to-date to be accepted and, wearing different clothes to impress people both of which explain the factor of being well-respected, $47 \%$ and $64 \%$ respectively responded never. Similarly, on using cost of clothing to determine one's status for respect, the majority of students, 54\% indicated never. A closer examination on the social factors and choice of clothing confirmed being well respected $(80 \%)$ as a cherished value in students selection of clothing even though they would like to have warm relations (42\%) and sense of belonging (68\%).

An examination on external influences in Table 3 shows that, $71 \%$ of students consider family opinion often more important than friends in their choice of clothing. Thirty eight percent feel more part of their family when dressed like family members. Students also emphasise they do not dress similar to friends, dress to belong nor choose clothing to impress or suit friends. However they would sometimes, involve friends in making clothing choices. This could also mean students feel uncomfortable when their clothing is different from those of others. Again they realised feeling more friendly and outgoing when dressed in certain clothing. Ranking of media influence on students' choice of clothing indicated that Television had the highest percentage influence of 35\%, followed by print media (Magazines/Newspaper) 29\%, and internet, $23 \%$. The remaining estimated at $14 \%$ claimed they were not influenced by the media but through other sources. This confirms Moschis and Moore's (1979) research into decision-making among the youth; that found that there is a positive relationship between the amount of television viewing and the extent to which an adolescent has brand preferences. Dibley (2004) also indicated that there is a correlation between brand recognition and commercial television viewing. This could be explained in the fact that students spend time watching television and reading print media. Forty percent indicated that external influences; sense of belonging; warm relations and being well respected influence their choice of clothing, an indication that most individuals' choice of clothing is determined from within. A confirmation of Sybers \& Roach, 1962, views that apparel is a manifestation of man's inner needs. However the social factor is quite significant in students' choice of clothing and should be given a close attention if the youth choice of clothing is undesirable.

Table 5: HO - Mean Ratings on External influences on Students' Choice of Clothing in terms of Gender

\begin{tabular}{|c|c|c|c|c|c|c|}
\hline & Male & & Fem & ale & & \\
\hline Item & M & SD & & M & t-cal & sig. (2-tailed) \\
\hline Warm relationship & 1.7 & 0.74 & 1.9 & 0.78 & -2.131 & 0.034 \\
\hline Similar to friends & 3.3 & 0.85 & 3.6 & 0.66 & -2.834 & 0.017 \\
\hline Dress like relatives & 2.5 & 1.10 & 2.8 & 1.04 & -2.366 & 0.019 \\
\hline
\end{tabular}

* M-Mean, SD-Standard Deviation, $t$-cal-Test Calculation, sig- Significance

Table 5 presents the results of the independent-samples t-test performed on external factors' influence on students' choice of clothing. The two independent groups of males and females were randomly selected. In respect of the social factors, equal variance was assumed for all except the sense of belonging $p=.032$, dressing similar to friends $p=.017$ and putting on different clothing to impress $p=.006$. Out of the sixteen factors presented for analyses, the independent sample $t$-test analyses determined four items having significant difference in students' choice of clothing. Among these items is one that belongs to the main factor of warm relationship. The warm relationship factor involves choosing clothing for close family companionship and intimate friendship with others. The values for students buying/getting new clothes for a special occasion when clothes are not similar to what friends are wearing had means score of $(\mathrm{M}=3.3, \mathrm{SD}=.85)$ for males and $(\mathrm{M}=3.6, \mathrm{SD}=.66)$ for females with t-test significant difference value of $(t$ $(205)=2.834, p=0.017)$. Feeling more part of family when clothed like relatives had mean score of $(M=2.5, S D=1.10)$ for males and $(M=2.8, S D=1.04)$ for females with a significant difference figure of $(t$ $(205)=2.366, \mathrm{p}=0.019)$.

As seen in Table 5, comparison of the means from the two independent groups suggests that there was statistically significant difference in the means with male students choosing clothing for warm relations $(M=1.7, S D=0.74)$ being less than female students $(M=1.9, S D=0.78)$. The difference in mean scores was significant $(t(205)=2.131, p=0.034)$. This is an elaboration substantiating earlier findings on psychological factors that point the male gender dominating at internal factors. Here again, the female gender is being projected as fashion followers. This is because they would choose clothing for warm relations, similar to friends, dress to belong and at the same time wish to choose clothing to suit relatives. This finding substantiates Hansen's (2004) view that the cultural norms on how to dress weigh down on 
women more heavily than men. In effect, women feel restrained in their freedom in their choice of clothing. The study also supports Dibley's (2004) assumption that an influential student of a different culture can easily affect the female colleagues with his or her values thereby causing them to choose similar clothing. That is, if these clothing would please people around. Therefore, the research hypothesis that, there is no significant difference in gender on external factors (warm relations) was rejected and it was concluded that there existed a significant difference attributed to gender regarding choosing clothing for warm relations. This result contradicts the result of Odeleye's (2000) hypothesis which indicates that there is no significant difference in the perception of male and female as regards the factors that influence adolescent clothing habits.

Table 6: HO - Mean Difference in factor Influence on Fashion and Accounting students' choice of Clothing

\begin{tabular}{|c|c|c|c|c|c|c|}
\hline & \multicolumn{2}{|c|}{ Fashion } & \multicolumn{2}{|c|}{ Accounting } & \multirow[b]{2}{*}{ t-cal } & \multirow[b]{2}{*}{ Sig.(2-tailed) } \\
\hline Item & $\mathbf{M}$ & SD & $\mathbf{M}$ & SD & & \\
\hline Sense of belonging & 1.7 & 0.85 & 1.3 & 0.58 & 4.062 & 0.000 \\
\hline Warm relationship & 2.0 & 0.79 & 1.6 & 0.72 & 3.329 & 0.001 \\
\hline Similar to friends & 3.6 & 0.66 & 3.4 & 0.82 & 2.540 & 0.012 \\
\hline Dress like friends & 3.8 & 0.55 & 3.6 & 0.85 & 2.245 & 0.026 \\
\hline Cost to determine status & 3.0 & 1.08 & 3.5 & 0.92 & -3.411 & 10.001 \\
\hline
\end{tabular}

* M-Mean, SD-Standard Deviation, t-cal-Test Calculation, sig- Significance

Table 6 presents the results of the independent-samples $t$-test performed on external influences on students' choice of clothing of two independent groups that are randomly selected (Fashion and Accounting). In respect of the external factors, equal variance was assumed for sense of belonging ( $p<$ 0.01 ). The test revealed that out of the sixteen factors presented for analyses, the independent sample ttest analyses certified four issues as having significant difference in students' choice of clothing socially. Among these factors were, sense of belonging and warm relationships. Fashion had the mean score of 1.7 and standard deviation of 0.85 while Accounting recorded 1.3 with standard deviation of 0.58 . The mean difference rating with regard to sense of belonging between Fashion and Accounting students was significant, ( $\mathrm{t}(205)$ 4.062, $p<.000)$. Furthermore, the mean score for Fashion students with regard to dressing similar to friends was 3.6, as against the score of 3.4 for Accounting students.

Another external influence on students' choice of clothing is to have warm relationships. Warm relationships had mean scores of 2.0 for Fashion and 1.6 for Accounting students. The mean difference in rating with regard to warm relations between the two programmes was significant, $(t$ (205) 3.329, $p=$ 0.001). The results implied that Fashion students considered dressing to belong and to have warm relationship more important than their counterparts in the Business Department. This supports Kaiser's (1997) view that clothing is an important factor in the interpretation of body image that affects the response behaviour of the beholder. Simmel (1973) also concluded that students who want to belong choose clothing to fit the group they are associated with. Regarding the use of cost of clothing to determine status, Accounting students consider it very necessary. They recorded the mean value of 3.5 against 3.0 for Fashion students. This could be explained in the fact that their course of study deals with finance and costing and they know or appreciate more the values and importance of something on the cost or worth of it. Again, the African is always willing to spend money to acquire the best which may be perceived by others as a sign of success. Osei- Poku and Adu-Agyemang (2008) are of the view that brand name apparel is important in enhancing individual's personal appearance. For the accounting students, it could also mean they believe they could use money to improve their outlook.

Comparison of the means from the two independent groups suggests that Fashion and Accounting students' choice of clothing for warm relations and sense of belonging showed a statistically significant difference. Therefore, the null hypothesis that there is no significant difference in programme of study on external factors was rejected due to the fact that there is significant difference in students' choice of clothing socially. There is the assumption that as much as some students would choose clothing for warm relations or sense of belonging, however, all students wished to be well respected by all regardless of the groups they belong. Therefore, policies taken by school authorities would have to consider these disparities. This is partly supported in Munson's (1984) work on personal values. He argued that there are difficulties in linking factor influence and brand choice in that, different value systems may lead to the same formal behaviour and students dressing according to school environment/department traits or 
similar value systems may lead to different behaviour. Moreover, he argued that students from the same culture might choose clothing differently to suit associations or friends.

\section{Conclusion}

There are always reasons why students choose clothing. While others depend on self-values some choose clothing to fit the environment they belong. Values, external and personal factors had an equally significant opportunity in influencing the dependent variable, clothing. However, the level at which each operate is different in an individual's life. One's profession, association and gender also play a significant role in influencing clothing decisions. Viewing findings in light of the social adaptation theory: it is explicitly clear that absorbing external information from various sources and integrating it into inner values modify existing internal values that might sometime meet external standards. Besides, an individual is accepted in the society when his or her choice of clothing matches societal norms. Though the individual sometimes would wish to live according to inner desires, there is always a driven force externally that directs once choice of clothing making it impossible to down play societal influence. It is recommended that school authorities should institute orientation programmes to educate students on the acceptable choice of clothing on campus. Again, there should be seminars to educate students on African values, choice of clothing and its impact on the individual and community as a whole.

\section{References}

Dibley, A. (2004). Uncovering the links between brand choice and personal values among young consumers in Spain and the UK. Doctoral thesis, Canfield University. Retrieved March 3, 2010, from www.marketing-trends-congrees.com.

Dixon, D. L. (2007). The influence of values and other social and psychological factors on the clothing and appearance of African American college students. Doctoral dissertation, Southern University and A \& M College. Retrieved March 4, 2010 from www.citeseerx.ist.psu.edu.

Fayokun, K. O., Adedeji, S. O. \& Oyebade, S. A. (2009). Moral crisis in higher institutions and the dress code phenomenon. Paper presented at Faculty of Law, Obafemi Awolowo University, Ile-Ife 00234, Nigeria.

Hansen, K. B. (2004). Dressing dangerously: Miniskirts, gender relations and sexuality in Zambia. In J. Allman (Ed), Fashioning Africa: Power and the Politics of Dress. Pp.166-185. Bloomington: Indiana University Press.

Kahle, L. R. (1996). Social values and consumer behaviour. In Seligman, C., Olson, J. M., \& Zanna, M. P. (Eds.), The Psychology of Values: The Ontario Symposium, Volume 8 (pp.135-151). Mahwah, NJ: Erlbaum.

Kaiser, S. B. (1997). The social psychology of clothing: Symbolic appearance in context (2nd ed.). New York: Capital Cities Media.

Langner L. (1959). The Importance of Wearing Clothes. Hastings House, 1959. University of Michigan.

Lynn, H. G. (2004). Fashioning modernity: Changing meanings of clothing in colonial Korea. Journal of International and Area Studies, 11, 75-93.

Marshal, S. C., Jacjson, O. H., Stanley, M. S. \& Kefgaf, M. (2000). touchine-Spectit, P. Individuality in Clothing Section and Person Appearance New Jersey Prentice Hall.

Moschis, G. P. \& Moore, R. L. (1979). Decision-making among the young: A socialization perspective. Journal of Consumer Research, 6, 45-50.

Munson, G. M. (1984). Personal values: considerations on their measurement and application to five areas of research inquiry. In E. Robert, Pitts Jr. \& G. Arch (Eds.), Personal Values and Consumer Psychology. (pp. 123-127) .Woodside: Lexington Books.

Okwu, O. J. (2006). A Critique of Students' Vices and the Effect on Quality of Graduates of Nigerian Tertiary Institutions. Paper presented at the Department of Agricultural Extension and Communication. University of Agriculture, Makurdi, Nigeria.

Odeleye, A. D. (2000). Psychological correlates of contemporary clothing behaviour of Nigerian undergraduate students. Unpublished doctoral thesis, Obafemi Awolowo University, Ile-Ife, Nigeria.

Osei-Poku, P. \& Adu-Agyemang, J. (2008). Achieving a goal of distinction in your dress. Journal of Science and Technology, 28(2), 135-150.

Pauly, D. (2008). Clothing code. Retrieved May 8, 2010 from http://www.answers.com/Clothing\%20code.

Simmel, G. (1973). Fashion. In G. Wills \& D. Midgley (Eds.), Fashion Marketing: an Anthology of Viewpoints and Perspectives. London: Allen and Unwin. 
Sybers, R. \& Roach, M. E. (1962). Clothing and human behaviour. Journal of Home Economics, 54(3), 184187.

Wallace. (1985). Advocating for Normal Birth with Normal Clothes Retrieved from: www.ncbi.nlm.nih.gov/pmc/articles/PMC1804322/

Watkins, S. M. (1977). the design of protective equipment for ice hockey. Home economics Research Journal, 5(5), 154-166.

Weber, R. P. (1990). Basic content analysis, Newbury Park, CA: SAGE Publications. 